Methods Participants from Europe and Canada took part in an online survey. Responses were collected from patients with IPF, and from physicians responsible for initiation of IPF treatment who had consulted with $\geq 5$ patients with IPF within 3 months. A mixture of WWP (monitor for $\geq 4$ months post-diagnosis in $\geq 50 \%$ of patients before initiating antifibrotic) and PP (initiate antifibrotic $<4$ months post-diagnosis in majority of patients) were recruited.

Results 43 patients and 254 physicians were surveyed between September and October 2016. Only 56\% of patients felt that they received enough information at diagnosis: $58 \%$ were advised that IPF is progressive; 44\% discussed prognosis; and $49 \%$ were told about treatment options. Although the majority of patients (93\%) preferred to receive information from their physician, most patients sought additional information about IPF (86\%), treatment (81\%), and/or prognosis (76\%). Most patients $(86 \%)$ felt that the ability of antifibrotic treatments to slow IPF progression was more important than sideeffect profiles. Overall, $86 \%$ of patients who had received antifibrotic therapy felt confident in managing side effects. WWP were less likely to discuss IPF prognosis than PP, even when asked specifically by patients (Table). 62\% and 38\% of patients with 'mild' IPF were treated with an antifibrotic $<4$ months post-diagnosis by PP and WWP, respectively. WWP were more concerned about treatment side effects than PP (28\% vs 17\%, respectively); PP were more concerned about disease progression than WWP ( $83 \%$ vs $72 \%$, respectively).

Conclusions We identified a disparity between the information patients want at diagnosis and the information they receive from physicians. Furthermore, Results suggest that PP may be more confident with the benefit-risk profile of antifibrotic treatment than WWP. A belief in effective treatment options may aid conversation with patients regarding their IPF diagnosis, thereby enabling patients to make informed treatment decisions.

Abstract M19 Table 1 Differences between physicians regarding disease prognosis and treatment decisions

\begin{tabular}{lll}
\hline & $\begin{array}{l}\text { WWP } \\
\text { n=118 }\end{array}$ & n=136 \\
\hline Mention typical IPF prognosis at diagnosis & $47 \%$ & $59 \%$ \\
Will avoid discussing typical prognosis/life expectancy even when & $51 \%$ & $33 \%^{*}$ \\
patient asks & & \\
Comfortable discussing IPF prognosis & $21 \%$ & $34 \%^{*}$ \\
Strongly believe they can make a big difference in IPF patients' lives & $29 \%$ & $45 \%^{*}$ \\
post-diagnosis & & \\
Agree that antifibrotic therapies significantly slow the progression of & $36 \%$ & $51 \%{ }^{*}$ \\
IPF & & \\
Reasons for not treating patients with 'mild' IPF with an antifibrotic: & & \\
Patient is asymptomatic/has few symptoms & $66 \%$ & $36 \%^{*}$ \\
Patient has stable disease & $65 \%$ & $33 \%{ }^{*}$ \\
Patient has good lung function & $58 \%$ & $38 \%{ }^{*}$ \\
Patient has a good quality of life & $53 \%$ & $27 \%^{*}$ \\
Patient has IPF that is progressing slowly & $53 \%$ & $26 \%{ }^{*}$ \\
\hline
\end{tabular}

\section{M20 THINK WELL, FEEL WELL. ENABLING PARTICIPANTS TO DEVELOP HELPFUL COPING STRATEGIES IN THE MANAGEMENT OF SEVERE ASTHMA CHALLENGES}

H Hope, G McCumesky, R Niven. University Hospitals South Manchester, Manchester, UK

\subsection{6/thoraxjnl-2017-210983.442}

Introduction The psychological difficulties of those living with severe asthma are well documented, and can impact on disease severity and patient self-management. ${ }^{1}$

Objectives Our objective is to help patients achieve what is important to them (values), whilst living with severe asthma, and in doing so should feel more emotionally resilient. Resilience may enhance managing the challenges and demands of their illness, and promote better self-management.

Method A three hour workshop involving a number of exercises was designed to elicit daily struggles in relation to asthma, how that impacts on what is important to participants in life, and the emotional impact. Participants were then encouraged as a group to evaluate how they managed such struggles in relation to their values, and whether the coping strategy was helpful in them achieving their values, or less helpful, inadvertently causing more distress. The workshop was evaluated with an idiosyncratic rating scale administered before and after the workshop.

Results 17 participants completed two workshops. Post-workshop mean scores demonstrated improved coping with asthma and a greater range of coping strategies. However, post-workshop mean average scores also demonstrated greater awareness of difficulties, that asthma felt more overwhelming, and was a greater barrier to achieving valued activities in life, compared to pre-workshop mean scores. Subjective feedback included, patients feeling less alone, more hopeful, and that having a complex illness should not coincide with the experience of depression or anxiety as the norm.

Conclusion The Results suggest that when patients are enabled to evaluate how effective their coping strategies are in relation to their values, asthma and associated demands seem more manageable. However, the Results also suggest that patients were reminded of some of their challenges/difficulties, and have realised through workshop attendance that their current ways of coping may not be the most helpful, and could ultimately be contributing to their distress/disease management. Whilst this was not an anticipated finding, it highlights the importance of access to psychological assessment and treatment.

\section{REFERENCE}

1. Asthma UK. Treatments for Depression 2016. Available at: https://www.asthma. org.uk/advice/inhalers-medicines-treatments/other/depression/ [Accessed: 9.06.2017].

\section{M21 PATIENT STORIES: THE USE OF NOVEL ANTI-FIBROTICS, PIRFENIDONE AND NINTEDANIB, IN THE MANAGEMENT OF IDIOPATHIC PULMONARY FIBROSIS, IPF}

S Enston-Newall. Cardiff University, Cardiff, UK

10.1136/thoraxinl-2017-210983.443 